each containing $10 \mathrm{ml}$. of the Freeman and Morrison ${ }^{1}$ medium solidified with agar. After incubating for $48 \mathrm{hr}$. at $25^{\circ} \mathrm{C}$., the diameters of the colonies were measured and to the nutrient agar surface was added $5 \mathrm{ml}$. of the antibiotic solution, each plate being rotated so that the solution formed a liquid film over the surface. The test plates and appropriate controls were then incubated for a further $18 \mathrm{hr}$. and the diameters remeasured. The interesting result here was that when exceedingly small concentrations of trichothecin $(0 \cdot 00018-0 \cdot 0018$ units $/ \mathrm{ml}$.) were used there was a well-marked stimulation of growth. In higher concentrations $(0 \cdot 0018-10$ units $/ \mathrm{ml}$.) the effect was fungistatic. Above these amounts there was a killing effect, and with 44 units $/ \mathrm{ml}$. the effect was wholly fungicidal.

A 'double-action' of long-chain unsaturated fatty acids on some bacteria has been reported ${ }^{2,3}$. When the concentration of trichothecin used was more than 10 units/mI., a pronounced swelling of the hyphal tips was noted, together with a bursting of some of these tips. The surface activity of the antibiotic is indicated by its reducing effect on surface tension.

It is suggested that trichothecin accelerates the bond-break phase of growth. In very minute amounts, trichothecin stimulates growth by slightly accelerating bond-break, enough to allow increased elongation but not enough to result in molecular disorganization. It is thought that it is this disorganization of the molecular make-up of the wall that in higher concentrations is responsible for the inhibition of growth and in still higher concentrations for the swelling and bursting of the tip.

In my experience, there is no report in the literature of a demonstration of the production of an antibiotic in sterile but otherwise untreated soil as well as in artificial media. This point was emphasized more than once at the seventh International Botanical Congress at Stockholm ${ }^{4}$. The following method has provided a positive demonstration of the production in sterile soil of trichothecin by Trichothecium roseum.

A sample of sterile garden soil $(p \mathrm{H}$ 6) was inoculated with $T$. roseum and incubated at $25^{\circ} \mathrm{C}$. for ten days. Shallow layers of this soil-culture were added to a series of Petri dishes and triple autoclaved together with dishes containing sterile soil as controls. After autoclaving, $10 \mathrm{ml}$. of Freeman and Morrison agar was poured into each plate in order to anchor the soil layer. An extra $20 \mathrm{ml}$. was then added to form a smooth-surfaced layer in which the soil was embedded. These plates were left for $20 \mathrm{hr}$. to allow diffusion into the medium of any antibiotic produced by the growth of the fungus. A standard amount of the test fungus was then placed at the centre of each plate, the plates being incubated at $25^{\circ} \mathrm{C}$. for four days. In each case there was a 9.6 per cent reduction in the diameter of the test fungus colony over the soil where $T$. roseum had been grown as compared with growth over sterile soil. After 18 days growth in the soil, a 10.9 per cent reduction in linear growth was recorded.

Department of Cryptogamic Botany,

D. G. Hessayon

University of Manchester. October 25.

${ }^{1}$ Freeman, G. G., and Morrison, R. I., Nature, 162, 30 (1948).

2 Pollock, M. R., Symposium of Soc. for Exp. Biol., 3, 193 (1949)

Kodicek, E., Symposium of Soc. for Exp. Biol., 3, 217 (1949).

- Rept. Proc. 7th Internat. Bot. Congr. Stockholm, 1950 (still in.

\section{The Fermentation-inhibiting Properties of Orange Oil}

THE recent communication by Zukerman ${ }^{1}$ leads us to give a preliminary note on our investigations on the antimicrobial properties of orange oil.

The starting point in these investigations was the observation that non-preserved fruit drinks, prepared from emulsified orange oil, inhibited the fermentation at $25^{\circ} \mathrm{C}$. of an inoculum of $10^{4}$ cells/ ml. Saccharomyces cerevisioe ${ }^{2}$.

Experiments were carried out with a semi-synthetic medium, containing 10 per cent sucrose and $0 \cdot 25$ per cent yeast autolysate ('Difco') at $p \mathrm{H}=5 \cdot 3 \pm 0 \cdot 2$. Florida orange oil (aldehydes, calculated as decylaldehyde $=1 \cdot 6$ per cent) was added in alcoholic solution to a final concentration of 1 per cent $\mathrm{v} / \mathrm{v}$ of alcohol. It appeared that 0.01 or more per cent of oil could retard the fermentation of the medium by the inoculum referred to in such a way as increasing the time required for complete fermentation (in blank experiments, $48 \mathrm{hr}$. or less) to at least $96 \mathrm{hr}$.

Since Guenther ${ }^{3}$ claims that the antimicrobial properties of essential oils such as orange oil are due to the terpenes rather than to the fraction containing oxygen derivatives, a Guinea orange oil (aldehydes $=$ 1.7 per cent) and both the terpenes and the oxygen compounds ( 3.6 per cent) derived from it by 'Duosol' extraction with 90 per cent methanol/pentan $\theta^{4}$ were studied. This investigation revealed that the terpenes possessed the same order of fermentation. inhibiting activity as the oil, whereas the oxygen fraction was inactive in concentrations occurring in additions of orange oil of the order of 0.1 per cent.

During the experiments the terpenes were stored in the refrigerator. They showed $[n]_{D^{20}}=1.4726$ and a peroxide value of $6.8 \mathrm{~m} . e q$. oxygen $/ \mathrm{kgm}$.

Research along these lines is being continued.

I am greatly indebted to Messrs. N.V. Chemische Fabriek "Naarden", Naarden, Netherlands, for their very helpful co-operation in procuring the essential oils and oil fractions used in. this investigation.

D. A. A. Mosser

Central Institute for Nutrition Research T.N.O., 61 Catharijnesingel,

Utrecht.

Oct. 8.

${ }^{1}$ Zukerman, I., Nature, 188. 517 (1951)

s Mossel, D. A. A., Nature, 166, 188 (1950).

"Guenther, F., "The Essential Oils", 1, 81 (van Nostrand, New York, 1948).

${ }^{4}$ Ruys, A. H., Perf. Ess. Oil Rec., 42, 118 (1951).

\section{Chlorosaccus ulvaceus Messik. and Vischer}

BeTween April and October of this year, a rare member of the Xanthophyceæ, Chlorosaccus ${ }^{2}$, a genus not previously recorded in the British Isles, has been collected on eight different occasions in east Yorkshire. It occurs in two much-shaded streams, one of them near South Cave, the other at Cottingham. From the former locality Chlorosaccus has now disappeared and in the latter it is extremely rare.

The pale yellow-green palmelloid colonies become macroscopic, irregular in shape and reach several centimetres in length; they are free-floating or entangled in submerged twigs. Actively swimming zoospores were obtained from material collected in June, July, September and (in smaller numbers) in 